\title{
(6) OPEN ACCESS The design and evaluation of a system for improved
surveillance and prevention programmes in
resource-limited settings using a hospital-based
burn injury questionnaire
}

\author{
Michael Peck, ${ }^{1}$ Henry Falk, ${ }^{2}$ David Meddings, ${ }^{3}$ David Sugerman, ${ }^{4}$ Sumi Mehta, ${ }^{5}$ \\ Michael Sage ${ }^{6}$
}

${ }^{1}$ Division of Community, Environment and Policy, Mel and Enid Zuckerman College of Public Health, University of Arizona Health Sciences Center, Tucson, Arizona, USA ${ }^{2}$ Office of Noncommunicable Disease, Injury, and Environmental Health, Centers for Disease Control and Prevention, Atlanta, Georgia USA

${ }^{3}$ Department of

Noncommunicable Diseases, World Health Organization, Geneva, Switzerland ${ }^{4}$ Division of Global Health Protection, Center for Global Health, Centers for Disease Control and Prevention, Atlanta, Georgia, USA ${ }^{5}$ Director of Programs, Global Alliance for Clean Cookstoves, Washington DC, USA

${ }^{6}$ The Public Health Institute, Oakland, California, USA

\section{Correspondence to} Dr Michael Peck, Arizona Burn Center, 2601 East Roosevelt Street, Phoenix, AZ 85008 USA; mpeck47@hotmail.com

Received 8 September 2015 Revised 23 February 2016 Accepted 25 February 2016

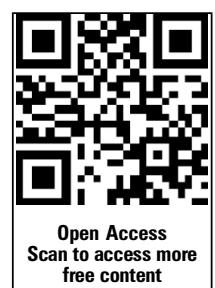

CrossMark

To cite: Peck M, Falk $\mathrm{H}_{\text {, }}$ Meddings $D$, et al. Inj Prev 2016;22:i56-i62.

\section{ABSTRACT}

Background Limited and fragmented data collection systems exist for burn injury. A global registry may lead to better injury estimates and identify risk factors. A collaborative effort involving the WHO, the Global Alliance for Clean Cookstoves, the CDC and the International Society for Burn Injuries was undertaken to simplify and standardise inpatient burn data collection. An expert panel of epidemiologists and burn care practitioners advised on the development of a new Global Burn Registry (GBR) form and online data entry system that can be expected to be used in resourceabundant or resource-limited settings.

Methods International burn organisations, the CDC and the WHO solicited burn centre participation to pilot test the GBR system. The WHO and the CDC led a webinar tutorial for system implementation.

Results During an 8-month period, 52 hospitals in 30 countries enrolled in the pilot and were provided the GBR instrument, guidance and a data visualisation tool. Evaluations were received from 29 hospitals (56\%).

Key findings Median time to upload completed forms was <10 min; physicians most commonly entered data (64\%), followed by nurses (25\%); layout, clarity, accuracy and relevance were all rated high; and a vast majority (85\%) considered the GBR 'highly valuable' for prioritising, developing and monitoring burn prevention programmes.

Conclusions The GBR was shown to be simple, flexible and acceptable to users. Enhanced regional and global understanding of burn epidemiology may help prioritise the selection, development and testing of primary prevention interventions for burns in resourcelimited settings.

\section{INTRODUCTION}

The overwhelming majority of death and disability due to burns across the world occurs in resourcelimited settings (RLSs). The 2012 Global Health Estimate of the WHO was that 267889 deaths were attributed to fire, heat and hot substances occurred globally, with nearly $80 \%$ these deaths, as well as $84 \%$ of disability-adjusted life-years (a measure of the years of life lost and the years lived in less than optimal health), occurring in low-income countries (LICs) and lower-middle- income countries (LMICs). ${ }^{12}$ In persons residing in an LIC, the RR of dying from fire, heat and hot substances was 7.6 times greater than for persons residing in highincome countries (HICs) (table 1). ${ }^{12}$

Burn mortality is strongly associated with social and economic disparities. Burn mortality rates correlate with national income level (gross domestic product), as well as inequitable distribution of wealth within countries. ${ }^{3}$

Vulnerable populations, such as women and children, are at higher risk of burn injuries. Risk factors for burns include the use of traditional cooking methods, low socio-economic status, domestic crowding, poor housing conditions and low education level. ${ }^{4}$ Burns that are intentionally inflicted, including suicides and domestic violence, are also a major component of the global burden of burns. Identified risk factors for intentional burn injuries include unstable relationships, drug and alcohol abuse, family conflict and the social implications of unemployment. ${ }^{5}$

The disproportionate impact of burns in RLSs is coupled with inadequate or absent data collection systems. Furthermore, the materials used to collect data in RLSs are created from variables that lack uniform definitions and are often single-hospital reports, making comparisons across settings difficult. $^{6} 7$ Multihospital registries have been developed, but most are not population-based. ${ }^{8}$ Experience with improvement of trauma care in RLSs has shown that trauma registries are crucial components of well-functioning trauma care systems, providing statistical data for epidemiology, performance improvement programmes, research and prevention. ${ }^{9-12}$

Existing burn registries are more heavily oriented towards clinical data and less towards epidemiological data, leaving a gap in information needed for creating burn prevention programmes. To improve this situation, we set out to determine whether a standard data collection instrument could be developed to capture the main risk factors and risk groups for burns. This concise questionnaire could be incorporated or linked with existing clinical data collection instruments, but its primary purpose was to collect data for burn prevention.

Treatment of severe burns is very costly, and even after treatment the patient often remains with disfigurement and disability. Primary prevention in this area is clearly the preferred approach. Burn prevention programmes in RLSs are being developed across the world. ${ }^{13}$ An example is the use of light-emitting diode and solar-powered lanterns to 
Table 1 Distribution of disability and mortality due to fire, heat and hot substances according to World Bank national income levels

\begin{tabular}{lrrrrr}
\hline & \multicolumn{1}{c}{ Global } & Low income & Lower middle income & Upper middle income & High income \\
\hline $\begin{array}{l}\text { Population }(\times 1000) \\
\%\end{array}$ & 7075456 & 846348 & 2506068 & 2429453 & 35 \\
$\begin{array}{l}\text { Burn-related mortality } \\
\quad \text { Number }\end{array}$ & 100 & 12 & 35 & 32545 & 1293593 \\
$\%$ & 267889 & 76281 & 136231 & 12 & 15301 \\
$\begin{array}{l}\text { Disability-adjusted life-years } \\
\quad \text { Number }\end{array}$ & 100 & 28 & 51 & 1885603 & 10 \\
$\quad \%$ & 17977694 & 5527500 & 9476044 & 53 & 1088545 \\
\hline From WHO. Global Health Estimates 2012. & 31 & & & 6
\end{tabular}

replace hazardous kerosene lamps in Madhya Pradesh, India. ${ }^{14}$ Yet, such programmes are largely emerging without the vital first step of an epidemiological description of the burn problem within a setting. Established public health practice recognises that the foundation for effective burn prevention programmes requires this epidemiological description. ${ }^{15}$ Sanghavi and associates performed a retrospective analysis of deaths from fire and flames in India during the year 2001. ${ }^{16}$ Their estimated total of $>163000$ deaths was six times the national estimate gathered from police sources. If under-reporting of burn-related deaths and disability has occurred throughout other RLSs, then the true magnitude of the burden of burn injuries is yet unidentified.

The Global Alliance for Clean Cookstoves (GACC), a publicprivate partnership, was launched by the UN Foundation in 2010 to save lives, improve livelihoods, empower women and protect the environment by creating a thriving global market for clean and efficient household cooking solutions. GACC works with a strong network of public, private and non-profit partners to help overcome the market barriers that currently impede the production, deployment and use of clean cookstoves in low/ middle-income countries. ${ }^{17}$ GACC recognises that scaling up efforts on this front requires good data on the distribution and risk factors of burn injuries. GACC's commitment has led to the creation of committees addressing data elements and surveillance, resulting in this pilot project, which was initiated to design, implement and pilot test a global burns registry. This project grew out of a convergence of interests between GACC and the International Society for Burn Injuries (ISBI)/burn prevention community, facilitated by injury prevention experts at the WHO and the CDC, and resulted in the active partnership to improve burn injury surveillance tools. This pilot project comprises two main elements. The first was the development of a hospital-based burn instrument for data related to causes and risk factors, acute morbidity and long-term disability. The second element was the ability to collate data from multiple hospitals. Some challenges inherent to data collection in RLSs include reduced hospital capacity, overloaded clinical settings and recordkeeping inconsistencies. We sought to develop a simple form that could be filled out after emergency care had been given and that would easily accommodate storage and uploading.

Specific goals for the design of the global burn injury data collection instrument were the following:

1. Provision of a clearer characterisation of the impact of burns and the circumstances in which burns are sustained.

2. Better targeting of primary prevention strategies, advocacy and identification of long-term socio-economic effects.
3. Standardisation of data collection and analysis by ensuring the ability to collate and work with data across all settings, especially RLSs, with non-ambiguous case definitions and instructions for use. It was agreed that at a minimum this instrument should include the core minimum dataset (MDS) proposed in the WHO/CDC Injury Surveillance Guidelines. $^{18}$

4. It was also recognised at the outset that the instrument would require guidance and training but that the overall level of this project should be pitched so as to ensure longterm sustainability and suitability for RLSs.

\section{METHODS}

The ISBI has defined 'burn' as an injury to the skin or other organic tissue primarily caused by thermal or other acute trauma. A burn occurs when some or all of the cells in the skin or other tissues are destroyed by hot liquids (scalds), hot solids (contact burns) or flames (flame burns). Injuries to the skin or other organic tissues due to radiation, radioactivity, electricity, friction or contact with chemicals are also identified as burns.

Stakeholders were identified and working groups established. Stakeholders included the GACC, the WHO and the CDC. A burn injury working group was established by the GACC to address the topic of burns and safe cookstoves. Four of the authors (SM, HF, DM and MP) representing the GACC, the CDC, the WHO and the ISBI identified the key stakeholders and organised the working groups, and using their existing extensive contacts identified and solicited experienced burn epidemiology researchers to participate in the working groups. The goal was to establish a mix of burn surgeons (subject matter experts), public health epidemiologists and surveillance/registry experts.

The overarching objective of creating the Global Burn Registry (GBR) data collection instrument was to ensure that data collected would provide information necessary for the primary prevention of burns. A secondary objective was that collection of these data would lead to improved knowledge of burn care practice. The instrument was designed for applicability in RLSs globally and to include non-ambiguous case definitions and instructions for use. The burn registry instrument included the core MDS proposed in the WHO-CDC Injury Surveillance Guidelines. ${ }^{9}$ Translation of the instrument was also considered highly desirable, although not mandatory; the GBR form has been translated from English into Arabic, French and 
Spanish. Also, any setting-specific adaptation deemed necessary would be accommodated by altering the names of response categories and mapping these names to a global, generic term, not by adding additional questions.

The partnership of GACC with the WHO and the CDC created the Surveillance and Data Technical Subgroup to address the linkage between household energy, stoves and burns, and specifically the need for improved surveillance and standardised surveillance tools to better understand and quantify burns related to cooking. Recommendations were developed for the best approaches to provide technical and other assistance to institutions and countries for building registry and surveillance data collection systems, although it was not the responsibility of the Surveillance and Data Technical Subgroup to implement such assistance. Subgroup members included 20 burn care practitioners and public health experts, most of whom have RLS experience. ${ }^{\mathrm{i}}$

Over approximately 9 months (October 2012 through June 2013), the subgroup considered and discussed over email an array of potential data elements for the tool. This began with agreement on an MDS and aetiology module (figure 1).

The starting point was a review of existing multinational burn registries in the English language; that is, the National Burn Repository (http://www.ameriburn.org/NBR.php) of the American Burn Association, the International Burn Injury Database (http://www.ibidb.org/) of England and Wales and the Burns Registry of Australia and New Zealand (http://www.med. monash.edu.au/epidemiology/traumaepi/burnsreg.html). The elements in the MDS were arrived at using a modified Delphi approach in which the working group leader would propose a single variable at a time, and sufficient time was allowed for all participants to voice opinions by email. Every variable in the MDS was finalised with the consensus of the entire group. An example of a variable that was considered but ultimately discarded was 'area of third-degree burn'. Although clearly significant in terms of morbidity and mortality, the task of accurately measuring the area of third-degree burn was believed beyond the capability of centres participating from RLSs. Remaining data elements were then defined and grouped according to content similarity. Once all questions and potential responses were agreed upon, they were organised within a layout that permitted relatively rapid paper-based data entry. This form was further revised on the basis of initial comments from the subgroup and then finalised.

An electronic platform for entering the data was then developed, based on the WHO DataCol platform, which allows for electronic uploading of data over the internet. DataCol provides for password-protected storage of data, and end users can access their own data and analyse it using a wide variety of statistical or spreadsheet software. A data visualisation tool was also developed in a widely used spreadsheet program that generates approximately 40 histograms and pie charts of an end user's data with a single click. A step-by-step guide for using the paper form and electronic uploading was next developed and revised

\footnotetext{
iSurveillance and data technical subgroup membership: Rajeev Ahuja (India), Alberto Bolgiani (Argentina), Shobha Chamania (India), Scott Corlew (USA), Gopalakrishnam Gururaj (India), Leila Kasrai (Canada), Asad Latif (USA), Saidur Mashreky (Bangladesh), Amr Moghazy (Egypt), Michael Peck (chair; USA), Tom Potokar (UK), David Sugerman (USA), Dehran Swart (South Africa), Ashley van Niekerk (South Africa), Brigitte Vilasco (Côte d'Ivoire), Hilary Wallace (Australia) and Shahla Yekta (Canada).
}

based on internal feedback from within the burn injury working group.

The GBR form allows for the recording of the mechanism of the burn and provides a nested set of follow-up questions for each main mechanism; also recorded are contributing factors, intentionality and severity of burn. In addition, the GBR form allows for gathering basic demographic and admission data, along with the discharge date and patient status, and whether a surgical procedure was performed. The information gathered was intended to provide a sufficiently detailed degree of contextual information about serious burns so that in each setting the main risk groups and the major contexts in which burns are sustained can be identified. This contextual information is an essential component of the public health approach and a necessary first step for more effective public health engagement on burn prevention, particularly in RLSs.

The GBR form was designed for use in hard copy, to be filled out by a clinical staff member, ideally a physician caring for the patient. Guidance material provided with the instrument makes it clear that hospitals are free to establish their own practices with respect to who completes and then uploads the form. The emphasis was on a short form, with clear unambiguous questions and response options to minimise interobserver variability. Once the paper form was completed, it was provided to personnel assigned to carry out the electronic phase of data entry. Staff members were trained to use the data collection tool. A question-by-question user manual was developed and distributed with the questionnaire to all participating pilot sites. The authors also provided a recorded webinar tutorial for the data collection process, and the guidance document was provided to the focal-point person for each hospital. Hospitals may have also instituted additional training on their own.

The guidance document recommended that physicians caring for the patient would be the ideal persons responsible for filling out the form. The guidance also made it clear that a reliable system needed to be established to ensure reliable data entry and long-term secure storage. Although the guidance provided with the instrument was comprehensive, oversight of the data collection and entry process was left to the contributing sites because no centralised mechanism was established for ensuring quality control.

The GBR form underwent a phase of pilot testing in hospitals around the world from 2013 to the first half of 2014. Based on information gained during the development phase, it was expected that it would take 5-10 min to complete the form for a single patient. Burn injuries requiring inpatient admission were thought to be well suited to data collection because hospital stays for burns severe enough to require hospitalisation tend to be measured in days, if not weeks. Therefore, the GBR form could be completed after the patient has been admitted to the ward, and thus should not interfere with resuscitation or the acute-care phase.

The intention of the pilot phase was to test the instrument and make any necessary changes, not to analyse individual facility data (although these data would be available to participating hospital staff on the website by using their registered username and passwords). The main focus of the network that developed the GBR form was on the data pertaining to the data collection instrument itself.

Pilot testing of the instrument began with identification of potential sites. It was agreed upon within the burn injury working group that pilot testing sites should be either hospitals designated as tertiary care centres for burns or hospitals seeing a sizeable number of patients with burns each month. A wide variety of communication channels were used to make hospitals 
World Health

Organization

\section{Global Burn Registry Data Collection Form}

Date electronically

entered:

(To be completed only by staff entering data electronically)

1. Indicate the respondent (person providing the information) and fill out all relevant boxes providing information about the patient.

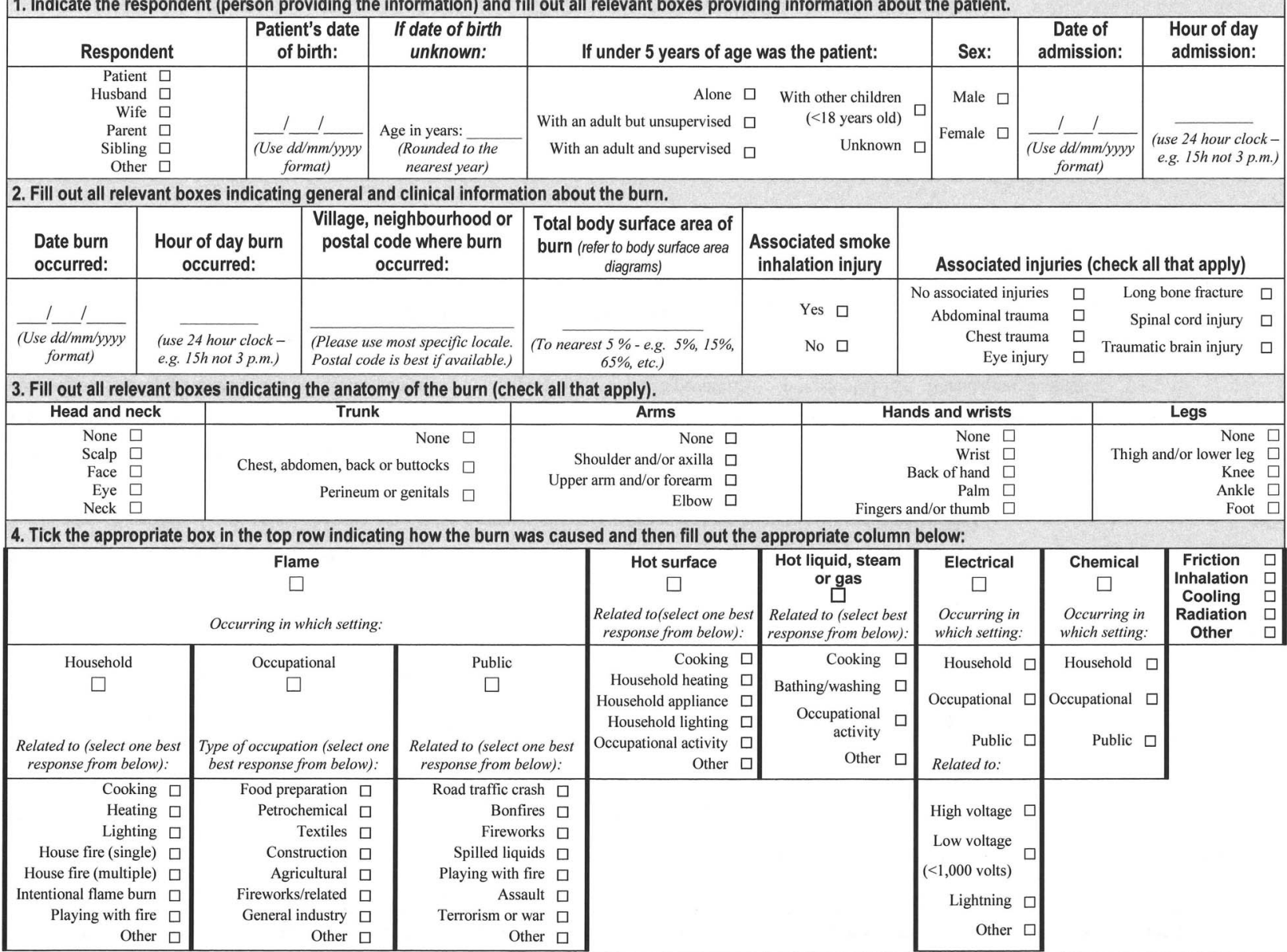

5. For burns involving either cooking/food preparation, household lighting, or household heating fill out all relevant boxes. For other burns, skip to question 6.

\begin{tabular}{|c|c|c|c|c|}
\hline Cooking & food preparation & & Household lighting & Household heating \\
\hline Burn caused by contact with: & \begin{tabular}{|r|} 
Burn involved: \\
\end{tabular} & & Burn caused by: & Burn caused by: \\
\hline $\begin{array}{rc}\text { Cook stove } & \square \\
\text { Cooking tool/vessel (pot, etc.) } & \square \\
\text { Burning fuel (wood, kerosene etc.) } & \square \\
\text { Cooked food or liquid } & \square \\
\text { Other } & \square\end{array}$ & $\begin{array}{r}\text { Deliberate movement (e.g. deliberate touch) } \\
\text { Accidental movement (e.g. fall/spill etc.) } \\
\text { Explosion } \\
\text { Fire in cooking area } \\
\text { Other }\end{array}$ & $\begin{array}{l}\square \\
\square \\
\square \\
\square \\
\square\end{array}$ & $\begin{array}{r}\text { Lamp/lantern igniting surrounding material } \\
\text { Deliberate movement touching lamp/lantern } \\
\text { Accidental movement touching lamp/lantern } \\
\text { Other }\end{array}$ & $\begin{array}{r}\text { Heating source igniting surrounding material } \\
\text { Deliberate movement touching heating source } \\
\text { Accidental movement touching heating source } \\
\text { Other }\end{array}$ \\
\hline Details of cooking area: & Fuel used for cooking: & & tern: & Energy source fo \\
\hline $\begin{array}{r}\text { Cooking area height (to ground): } \\
\text { Under } 0.9 \mathrm{~m} \text { (3 feet) } \\
0.9 \mathrm{~m} \text { (3 feet) or higher } \square \\
\text { Unknown } \\
\text { Cooking and living areas separate? } \\
\text { Yes } \\
\text { No } \square\end{array}$ & 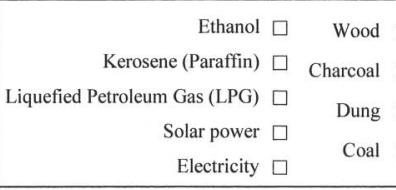 & $\begin{array}{l}\square \\
\square \\
\square \\
\square\end{array}$ & $\begin{array}{r}\text { Kerosene (Paraffin) } \square \\
\text { Electric } \square\end{array}$ & $\begin{array}{r}\text { Traditional biomass (wood, charcoal, dung) } \\
\text { Coal } \\
\text { Kerosene (Paraffin) } \\
\square \\
\text { Liquefied Petroleum Gas (LPG) } \\
\text { Natural gas } \\
\text { Electricity } \\
\text { Other } \quad \square\end{array}$ \\
\hline
\end{tabular}

6. Burn caused intentionally? Intentional self-harm $\square \quad$ Assault $\square \quad$ Unintentional $\square \quad$ Undetermined intent $\square$

7. If "Undetermined intent" was selected above, what is the degree of clinical suspicion that the burn was caused intentionally?

$$
\text { None } \square \quad \text { Low } \square \quad \text { Medium } \square \quad \text { High } \square
$$

8. If the patient is 15 years or older, is the patient literate? $\quad$ Yes $\square \quad$ No $\square \quad$ Unknown $\square$

9. Contributing factors: $\quad$ None $\square \quad$ Alcohol $\square \quad$ Drug $\square \quad$ Epilepsy $\square \quad$ Dementia $\square \quad$ Psychiatric illness $\square \quad$ Physical or mental disability $\square \quad$ Other $\square$

10. Number of people burned in this incident: 1 person $\square \quad 2$ people $\square \quad 3-5$ people $\square \quad 6-9$ people $\square \quad 10$ and more people $\square$

\begin{tabular}{|c|c|c|c|c|c|c|}
\hline Surgery during this hospital stay? & Date of discharge: & Hour of day patient discharged: & \multicolumn{4}{|c|}{ Condition on discharge from facility: } \\
\hline Yes $\square$ & & & $\begin{array}{l}\text { Dead } \\
\text { Transferred to another facility }\end{array}$ & $\square$ & $\begin{array}{l}\text { Discharged home with disability } \\
\text { Discharged home without disability }\end{array}$ & $\begin{array}{l}\square \\
\square\end{array}$ \\
\hline No $\square$ & (Use dd/mm/yyyy format) & (use 24 hour clock-e.g. 15 h not 3 p.m.) & Left against medical advice & $\square$ & Unknown & $\square$ \\
\hline
\end{tabular}

Figure 1 Global burn registry form. ${ }^{19}$ 
treating burns aware of the pilot test. Criteria for hospital participation in the pilot study are provided in box 1 .

A number of ethical aspects were considered and addressed. The risks to the patients with burns were minimal because it was advised that data collection take place only after emergency care had been given; and few elements within the instrument could be used to personally identify an individual. In this pilot project, the actual data from the patient questionnaires were not tabulated or analysed for any research purpose. What was assessed were the impressions of the participating burn units concerning the feasibility of administering the questionnaire in their clinical setting along with impressions regarding the instrument's utility, accuracy and relevance to burn injury in the pilot test settings.

At the completion of the primary data collection phase, a post-pilot survey was circulated to the participating burn centres. The survey was submitted to all burn centres recruited to the study, including those centres that did not submit data to the project. The survey requested pilot study feedback and was circulated and could be returned via email. The feedback obtained from this questionnaire was used to analyse system usefulness and feasibility of use.

\section{RESULTS}

Over 8 months, registered participants were provided the GBR instrument, guidance materials and the data visualisation tool. Detailed information regarding the participants is listed in table 2.

During July and August 2014, completed evaluation forms were received from 29 (56\%) hospitals. Of those, 26/29 (90\%) hospitals completed the paper forms and uploaded data. Two hospitals $(7 \%)$ completed the paper forms but did not upload the data, one because internet services were not available and one because internet service was too expensive. The remaining hospital, which neither completed the paper forms nor uploaded data, noted the need to have the form translated into Ukrainian.

The median time to complete or upload the form was $<10 \mathrm{~min}$. Approximately $30 \%$ of participants were able to complete the form in $\leq 5 \mathrm{~min}$, but $30 \%$ also required $\geq 20 \mathrm{~min}$ for completion. In contrast, $37 \%$ were able to upload the form in $\leq 5 \mathrm{~min}$, but only $11 \%$ required $\geq 20 \mathrm{~min}$ to complete uploading.

Physicians were the personnel most commonly involved in data entry (64\%), followed by nurses (25\%). Only $4 \%$ of the hospitals used clerical staff for data entry, and $7 \%$ used multiple personnel with various backgrounds.

The layout, clarity, accuracy and relevance of the paper form were all rated high. Occasionally, under clarity of questions,

\section{Box 1 Criteria for hospital participation in pilot study}

- Hospitals anticipate $\geq 6$ burn-related inpatient admissions per month.

- Hospitals must enter basic information about their facility using a brief online participant registration form.

- Hospitals agree to use the Global Burn Registry form for a minimum of 3 months on all burn-related inpatients.

- Hospitals agree to upload their burn-related inpatient data using a form provided on a web-based data entry platform.

- Hospitals agree to complete the online pilot phase evaluation form. comments suggested additional options for selection, but the majority of respondents were satisfied with the structure of the questions and response options. Thirty per cent of respondents, however, felt the discharge section required clarification and better definition of options. Smoke inhalation injury is a clinically important factor determining severity and prognosis; however, $>20 \%$ of respondents believed that the accuracy of responses was low. Similarly, $>20 \%$ believed responses to the query of intent were likely to be inaccurate. The vast majority $(85 \%)$ believed the GBR to be 'highly valuable' for prioritising/ developing/monitoring burn prevention programmes. Of the $40 \%$ who used the data visualisation tool, $>90 \%$ found it very useful.

\section{DISCUSSION}

A standardised instrument for a hospital-based burn injury surveillance registry was successfully completed and tested, establishing the potential for the standardised collection of global data on burn injuries. Web-based reporting was successfully demonstrated. Sponsoring agencies plan to revise the GBR instrument on the basis of pilot test feedback and to roll out a finalised GBR instrument to enable ongoing globally standardised data collection efforts on burns.

The post-pilot questionnaire identified both strengths and areas for improvement. Respondents indicated that limitations in staff motivation and training led to challenges in data collection and entry, exacerbated by shortages in administrative support and office supplies. A recurring theme in many of the questionnaire responses was the lack of resources for accurate and timely data entry. The burden of time was greater for completion of the form than for uploading the data, affirming the challenge of chart management and data collection. While many respondents replied that they would like to see the future implementation of an electronic recording and submission system, the majority of facilities indicated that they would face difficulties posed by the lack of staff or computer equipment necessary to implement such a system.

The evaluation results suggest that there would be few significant potential obstacles to the establishment of a GBR with standardised collection of data. The results were helpful in making some indicated modifications to the instrument. These are now implemented and the data collection platform is being changed from DataCol to DataForm, another data collection platform maintained by the WHO. DataForm provides a number of performance advantages over DataCol, including the possibility of automating some data quality control cheques both at input stages and in the reporting phase. Maintenance of the data collection platform and secure storage of data, oversight of the database, as well as provision of a reporting function will be assured by the WHO. Local costs for hospitals to participate (such as printing paper forms, the availability of computer with internet connection and staff time) will continue to be borne by the hospitals.

The active collaboration among the GACC, the ISBI/burn community, the WHO and the CDC has initially focused on the 'development of standardised data collection tools. Subsequent phases will focus on the global aggregation of data including that from existing registries in $\mathrm{HIC}$ and from ongoing national or regional efforts in LMIC such as the national programme underway in India. This has been a stepwise effort, and with the success of this initial pilot further funding and resources will be sought for expanding the effort into a coordinated global surveillance system for burn injury prevention data. 
Table 2 Participants in pilot test

\begin{tabular}{|c|c|c|c|c|c|c|}
\hline Country & City & $\begin{array}{l}\text { Hospital } \\
\text { beds }\end{array}$ & Patients with burn per month & Uploaded data & $\begin{array}{l}\text { Completed } \\
\text { evaluation }\end{array}$ & $\begin{array}{l}\text { World Bank } \\
\text { income group }\end{array}$ \\
\hline \multirow[t]{2}{*}{ Afghanistan } & Kabul & 35 & 12 & No & $\mathrm{N} / \mathrm{A}$ & Low \\
\hline & Kabul & 15 & 40 & No & $\mathrm{N} / \mathrm{A}$ & Low \\
\hline Australia & Perth & 450 & 25 & Yes & No & High \\
\hline Bangladesh & Dhaka & 20 & 6 & Yes & Yes & Low middle \\
\hline Costa Rica & San José & 220 & 20 & No & No & High middle \\
\hline China & Beijing & 1000 & 10 & Yes & Yes & High middle \\
\hline Côte d'Ivoire & Abidjan & 17 & 10 & Yes & Yes & Low middle \\
\hline \multirow[t]{3}{*}{ Germany } & Nuremberg & 2500 & 9 & No & N/A & High \\
\hline & Munich & 800 & 15 & Yes & No & High \\
\hline & Cologne & 1000 & 12 & No & $\mathrm{N} / \mathrm{A}$ & High \\
\hline \multirow[t]{2}{*}{ Egypt } & Mansoura & 400 & 10 & Yes & Yes & Low middle \\
\hline & Ismailia & 600 & 20 & Yes & Yes & Low middle \\
\hline Ghana & Kumasi & 12 & 10 & Yes & Yes & Low middle \\
\hline \multirow[t]{2}{*}{ Gambia } & Banjul & 800 & 15 & Yes & Yes & Low \\
\hline & Serrekunda & 114 & 10 & Yes & Yes & Low \\
\hline Guatemala & Ciudad de Guatemala & 926 & 31 & Yes & Yes & Low middle \\
\hline \multirow[t]{2}{*}{ India } & Mumbai & 50 & 20 & No & $\mathrm{N} / \mathrm{A}$ & Low middle \\
\hline & Visakhapatnam & 1047 & 50 & Yes & Yes & Low middle \\
\hline \multirow[t]{3}{*}{ Iran } & Kermanshah & 250 & 30 & Yes & Yes & High middle \\
\hline & Tehran & 120 & 300 & Yes & Yes & High middle \\
\hline & Sari & 250 & 100 & No & N/A & High middle \\
\hline Israel & Ramat Gan & 1800 & 8 & No & $\mathrm{N} / \mathrm{A}$ & High \\
\hline \multirow[t]{3}{*}{ Kenya } & Nairobi & 1800 & 90 & Yes & Yes & Low middle \\
\hline & Nakuru & 600 & 10 & Yes & Yes & Low middle \\
\hline & Nairobi & 98 & 12 & No & $\mathrm{N} / \mathrm{A}$ & Low middle \\
\hline Sri Lanka & Colombo & 910 & 20 & Yes & Yes & Low middle \\
\hline Morocco & Settat & 268 & 2 & No & $\mathrm{N} / \mathrm{A}$ & Low middle \\
\hline Mexico & Ciudad de México & 1 & 1 & No & $\mathrm{N} / \mathrm{A}$ & High middle \\
\hline Mongolia & Ulan Bator & 80 & 120 & No & $\mathrm{N} / \mathrm{A}$ & High middle \\
\hline Niger & Galmi & 140 & 5 & Yes & Yes & Low \\
\hline \multirow[t]{3}{*}{ Nigeria } & Ilorin & 600 & 7 & No & $\mathrm{N} / \mathrm{A}$ & Low middle \\
\hline & Zaria & 550 & 15 & Yes & Yes & Low middle \\
\hline & Ibadan & 830 & 7 & No & No & Low middle \\
\hline \multirow[t]{3}{*}{ Nepal } & Kathmandu & 9 & 20 & Yes & Yes & Low \\
\hline & Kathmandu & 50 & 12 & Yes & No & Low \\
\hline & Kathmandu & 50 & 5 & No & $\mathrm{N} / \mathrm{A}$ & Low \\
\hline Oman & Muscat & 12 & 30 & Yes & Yes & High \\
\hline Pakistan & Karachi & 200 & 25 & Yes & Yes & Low middle \\
\hline Peru & Lima & 450 & 25 & No & No & High middle \\
\hline Tanzania & Dar es Salaam & 1300 & 35 & Yes & Yes & Low \\
\hline The UK & Liverpool & 1000 & 300 & No & No & High \\
\hline Ukraine & Lviv & 300 & 30 & Yes & Yes & Low middle \\
\hline \multirow[t]{2}{*}{ Viet Nam } & Hanoi & 310 & 300 & Yes & Yes & Low middle \\
\hline & Ho Chi Minh City & 1200 & 240 & No & $\mathrm{N} / \mathrm{A}$ & Low middle \\
\hline \multirow[t]{8}{*}{ South Africa } & Durban & 846 & 22 & No & N/A & High middle \\
\hline & Pretoria & 400 & 10 & Yes & Yes & High middle \\
\hline & Empangeni & 564 & 20 & No & $\mathrm{N} / \mathrm{A}$ & High middle \\
\hline & Kimberley & 746 & 15 & Yes & Yes & High middle \\
\hline & Pietermaritzburg & 800 & 27 & No & Yes & High middle \\
\hline & Soweto & 3200 & 20 & No & Yes & High middle \\
\hline & Johannesburg & 346 & 8 & Yes & Yes & High middle \\
\hline & Cape Town & 300 & 120 & Yes & Yes & High middle \\
\hline Summary & 52 & & & & $29(55.7 \%)$ & \\
\hline
\end{tabular}

From World Bank national income level designations.

Totals: participants included 52 hospitals from 30 countries: 5 high-income countries, 7 high-middle-income countries, 13 low-middle-income countries and 5 low-income countries.

\section{SUMMARY OF SYSTEM ATTRIBUTES}

Experience with this data collection system allowed us to arrive at conclusions regarding various attributes of the registry.
Both in terms of structure and ease of operation, this data collection system was simple, allowing first-time users access with minimal training. 
- Although not pilot tested over a long time period, this system demonstrates flexibility, supporting the modification of questions and paper-based collection in countries unwilling to send data to the WHO via the internet.

- The system is timely, with data immediately available to facilities, automatically updated and retabulated.

- Finally, the system demonstrated high stability without corruption, hacking or downtime for maintenance.

\section{LIMITATIONS}

Only 52 hospitals worldwide chose to participate in the pilot test and just over half $(56 \%)$ of those hospitals submitted data leading to selection bias. The Ministry of Health in India performed its own pilot test, but the data from those 16 participating hospitals could not be included in this report because of agreements with the Indian government about data sharing. Alternative technologies were considered (such as using tablets and cell phones for data collection and submission), but were not implemented in this phase of the study. Participation occurred at the level of the individual hospital, and it is possible that with motivation, promotion and support from local ministries of health and other stakeholders, participation could have been much higher. We were also not able to demonstrate how the collected data would be used in prevention activities.

\section{What is already known on the subject}

- Although severe burns are a major global public health problem, only limited epidemiological data have been available, and few of the proven primary prevention strategies are applicable in resource-limited settings.

- Prioritising the selection, development and testing of primary prevention interventions for burns in resource-limited settings can and should be informed by the epidemiology of burns in these settings.

\section{What this study adds}

- The WHO and a global network of epidemiologists and burn care practitioners have developed and piloted a new system for gathering burn-related data, which can be expected to be used in either resource-abundant or resource-limited settings.

- This system's data collection instrument (form) had three functions: (1) to characterise the main risk factors and mechanisms for burns requiring inpatient care, (2) to characterise the main risk groups for burns requiring inpatient care and ( 3 ) be designed for use without modification and around the world.

- After pilot testing, this form was shown to be simple, flexible and acceptable to users.
Acknowledgements The authors are very grateful for all the time and energy contributed to this project by the other members of the Surveillance and Data Technical Subgroup. Additionally, the authors would like to express their gratitude for the medical editing skills of Ms Andrea Sattinger.

Disclaimer The authors alone are responsible for the views expressed in this article and they do not necessarily represent the views, decisions or policies of the institutions with which they are affiliated.

Competing interests None declared.

Ethics approval Review of this project was performed by the Institutional Review Board (IRB) for the Protection of Human Subjects at Maricopa Integrated Health System, Phoenix, Arizona. This study was deemed exempt from IRB oversight because the project included no personal health or other identifying information for patients.

Provenance and peer review Commissioned; externally peer reviewed.

Open Access This is an Open Access article distributed in accordance with the Creative Commons Attribution Non Commercial (CC BY-NC 4.0) license, which permits others to distribute, remix, adapt, build upon this work non-commercially, and license their derivative works on different terms, provided the original work is properly cited and the use is non-commercial. See: http://creativecommons.org/ licenses/by-nc/4.0/

\section{REFERENCES}

1 World Health Organization. Health Statistics and Information Systems: Cause-Specific Mortality Estimates for 2000-2012. http://www.who.int/healthinfo/ global_burden_disease/estimates/en/index1.html

2 World Health Organization. Health Statistics and Information Systems: Disease Burden Estimates for 2000-2012. http://www.who.int/healthinfo/global_burden_ disease/estimates/en/index2.html

3 Peck M, Pressman MA. The correlation between burn mortality rates from fire and flame and economic status of countries. Burns 2013;39:1054-9.

4 Dissanaike S, Rahimi M. Epidemiology of burn injuries: highlighting cultural and socio-demographic aspects. Int Rev Psychiatry 2009;21:505-11.

5 Peck MD. Epidemiology of burns throughout the World. Part II: intentional burns in adults. Burns 2012;38:630-7.

6 Ahmadi M, Alipour J, Mohammadi A, et al. Development of a minimum data set of the information management system for burns. Burns 2015;41:1092-9.

7 Dale EL, Mueller MA, Wang L, et al. Epidemiology of operative burns at Kijabe Hospital from 2006 to 2010: pilot study of a web-based tool for creation of the Kenya Burn Repository. Burns 2013;39:788-95.

8 Fuzaylov G, Murthy S, Dunaev A, et al. Improving burn care and preventing burns by establishing a burn database in Ukraine. Burns 2014;40:1007-12.

9 Nwomeh BC, Lowell W, Kable R, et al. History and development of trauma registry: lessons from developed to developing countries. World J Emerg Surg 2006;1:32. http://www.wjes.org/content/1/1/32 (accessed 10 Dec 20125).

10 Schultz CR, Ford HR, Cassidy LD, et al. Development of a hospital-based trauma registry in Haiti: an approach for improving injury surveillance in developing and resource-poor settings. J Trauma 2007;63:1143-54.

11 Kobusingye OC, Lett RR. Hospital-based trauma registries in Uganda. J Trauma 2000;48:498-502.

12 O'Reilly GM, Joshipura M, Cameron PA, et al. Trauma registries in developing countries: a review of the published experience. Injury 2013;44:713-21.

13 Mock C, Peck M, Julliard C, et al, eds. Burn prevention: success stories, lessons learned. Geneva: World Health Organization, 2011.

14 Chamania S, Chouhan R, Awasthi A, et al. Pilot project in rural western Madhya Pradesh, India, to assess the feasibility of using LED and solar-powered lanterns to remove kerosene lamps and related hazards from homes. Burns 2015;41:595-603.

15 Mock C, Peck M, Peden M, et al., eds. A WHO plan for burn prevention and care. Geneva: World Health Organization, 2008.

16 Sanghavi P, Bhalla K, Das V. Fire-related deaths in India in 2001: a retrospective analysis of data. Lancet 2009;373:1282-8.

17 Peck MD, Kruger GE, van der Merwe $A E$, et al. Burns and fires from non-electric domestic appliances in low and middle income countries: part I. The scope of the problem. Burns 2008;34:303-11.

18 Holder Y, Peden M, Krug E, et al, eds. Injury surveillance guidelines. Geneva: World Health Organization, 2001.

19 Meddings DR. Harmonising data collection for burns. Inj Prev 2013;19:444. 